\title{
Novas tecnologias da informação e blocos econômicos mundiais: a experiência da União Européia
}

\author{
Helena Maria Martins Lastres* \\ Marta Pinbeiro Aun **
}

\section{Resumo}

Debate sobre o novo ambiente da informação e o impacto das novas tecnologias, dando-se especial ênfase às relações com um bloco econômico mundial, a União Européia.

Palavras-chave: globalização, tecnologias da informação, blocos econômicos, União Européia.

\section{Introdução}

Durante as duas últimas décadas, a economia internacional vem atravessando um período de profunda transformação e reestruturação, envolvendo a conformação e difusão de um novo padrão técnico, econômico, informacional, institucional, social e geopolítico.

No conjunto de tais mudanças encontra-se o desenvolvimento e a difusão das denominadas tecnologias de informação e comunicação, as quais tornaram-se a base do rápido desenvolvimento da produção e do comércio internacionais, associadas a - além de importantes mudanças técnicas - várias mudanças geopolíticas, econômicas, organizacionais, institucionais, sociais e culturais, que se relacionamde maneira dinâmica.

Dentro desta ótica, consideram-se como intrinsicamente relacionados os processos de conformação do novo padrão técnico-econô-

*Helena Maria Martins Lastres - PhD em Industrialização e Tecnologia, SPRU, Universidade de Sussex, Inglaterra - Pesquisadora e Professora do Programa de Pós-Graduação em Ciência da Informação - PPCI, Universidade Federal do Rio de Janeiro.

**Marta Pinheiro Aun - Professora da Escola de Biblioteconomia da UFMG, Doutoranda do Programa de Pós-Graduação em Ciência da Informação - PPCI, Universidade Federal do Rio de Janeiro.

Comun. Inf., v.2, n. 1, p. 98-110, jan./jun. 1999 
mico, a aceleração do processo de globalização, a reorganização do sistema geopolítico mundial e a formação de blocos econômicos regionais.

No novo cenário ressalta particularmente o ainda mais estratégico papel conferido à área de informação. As atividades que vêm apresentando os mais elevados índices de crescimento são aquelas mais intensivas em informação, a qual passa a ser vista como o insumo fundamental do novo padrão de desenvolvimento. Por outro lado, o cada vez mais acelerado e extensivo uso da informática e das telecomunicações vem revolucionando as próprias formas de produção, acesso, tratamento e disseminação de informações.

Como decorrência de tais mudanças, caracteriza-se atualmente uma tendência, que vem sendo descrita de diferentes formas pela literatura especializada. Alguns autores referem-se à ocorrência de uma "revolução informacional" dando origem a uma época configurada como "sociedade da informação". Assim, atenção redobrada passa a ser conferida ao desenvolvimentoda área da informação, no que concerne às políticas definidas tanto no âmbito de organizações, quanto de países e blocos de países.

O objetivo central deste trabalho é o de discutir o advento e a rápida difusão das novas tecnologias da informação, suas características e consequências principais, a associada aceleração do processo de globalização e a conformação de blocos regionais; assim como analisar formas possíveis de respostas dadas aos novos desafios introduzidos.

Neste último caso será focalizada a experiência do bloco geopolítico-econômico (e não apenas comercial) há mais tempo estruturado e ativo - a União Européia. Neste caso, que oferece exemplos e lições de extrema relevância, contempla-se a definição e implementação de políticas do bloco como um todo, diretamente articulado políticas nacionais e coordenando as diferentes orientações de desenvolvimento econômico, industrial, social e informacional.

\section{As novas tecnologias da informação e conformação da sociedade da informação}

A dinâmica econômica internacional mudou significativamente na década de 80 . Em primeiro lugar, evidenciou-se a transição do 
Por outro lado, o cada vez mais acelerado e extensivo uso da informática e das telecomunicações vem revolucionando as próprias formas de produção, acesso, tratamento e disseminação de informações. O salto, tanto quantitativo como qualitativo, registrado neste área nos últimos anos mostra-se impressionante.

A área de informação passa, portanto, a assumir papel ainda mais visível e estratégico na nova ordem estabelecida, baseando e alavancando as novas possibilidades de crescimento. Este fato é ressaltado tanto nas análises recentes sobre dinâmica econômica, quanto nas análises sobre tendências de emprego. Tais análises mostram que os setores que apresentam as maiores taxas de crescimento, assim como de absorção de recursos humanos são aqueles mais intensivos em informação.

Como uma das consequências principais de tais constatações, informação passa a ser vista nesse novo cenário como seu insumo dinâmico fundamental. Assim é que diversos autores referem-se à atual nova ordem mundial criando e utilizando termos tais como era ou sociedade da informação, resultante da "revolução informacional" (traçando um paralelo com a chamada revolução industrial ocorrida nos finais do século XVIII). Da mesma forma, pode ser compreendida a maior atenção que os diferentes países e blocos geopolíticos vêm dando à criação e desenvolvimento de amplas e complexas infra-estruturas de informação e comunicações, assim como de políticas de promoção à área de informação.

\section{Tecnologias da informação e processo de globalização}

Os estudos já produzidos sobre a atual fase do movimento de globalização - sejam eles de caráter econômico, sociológico, político ou cultural - coincidemcom a identificação de dois fenômenos correlacionados como principais catalizadores desse processo. ${ }^{1}$ Por um lado, salienta-se o crescente movimento de liberalização e desregulação dos mercados em nível mundial (e, sobretudo, a desregulação dos sistemas financeiros e dos mercados de capitais).

Por outro lado, destaca-se exatamente o acima referido desenvolvimento e difusão do novo padrão de acumulação baseado nas tecnologias da informação e a conformação da sociedade da informação. Neste sentido, ressalta-se particularmente o avanço e a difusão 


\section{2}

das TICs e dos novos formatos organizacionais associados promovendo e acelerando em escala mundial a interconecção entre vários tipos de organizações espalhadas em diversas regiões do mundo. Assim, a difusão acelerada de tal novo padrão propicia os meios técnicos para que de fato articulem-se em tempo real organizações e instância geograficamente distantes. Aliás, conforme destacado por alguns autores, a real impressão de que o mundo "globalizou-se" deve-se ao fato de atualmente a informação ser "instantânea".

Devido particularmente ao recente e significativo aumento da amplitude e a velocidade de circulação de bens e serviços, informações, valores e símbolos culturais, destaca-se a abertura de novos horizontes de tempo e espaço, historicidade e territorialidade. Conforme destacado por Ianni (1995) uma das principais características dos novos tempos é que "todas as velocidades são ultrapassáveis ... velocidades excepcionais anulam e inauguram fronteiras reais e invisíveis, imaginárias e virtuais, reduzindo e transformando as distâncias ... Tem-se a impressão que foram dissolvidas as fronteiras, montanhas, mares, desertos, línguas, culturas, moedas, civilizações e religiões" (p. 168). Desta forma, é explicado (mas não justificado) o surgimento das teses sobre o final da história e da geografia e da pós-modernidade.

Dentre os principais aspectos geopolíticos associados à atual fase de expansão desta nova formatação salienta-se um de particular interesse para a discussão proposta neste trabalho: a reorganização espacial da atividade econômica e dos fluxos de informação, a formação de blocos econômicos e a re-hierarquização dos centros decisóriose de poder.

Paralelamente à atual aceleração verificada no processo de globalização, alguns autores destacam a realocação internacional da atividade produtiva e dos fluxos de comércio e informações, concentran-se aceleradamente na denominada Tríade (Estados Unidos, Japão e países da Europa Ocidental), que vêm se consolidando como blocos econômicos hegemônicos mundiais. Outros autores chegam, inclusive, a caracterizar a globalização como um processo que amplia as diferenças entre os atores e espaços envolvidos.

Touraine (1995) por exemplo, destaca que com a globalização, uma nova ordem econômica é estabelecida onde crescem as interdependências entre os atores de todo o tipo, mas que não é de jeito nenhum sinônimo de convergência e, muito menos, de solidariedade crescentes. Outros, como Bergesen (1982) destacam inclusive

Comun. Inf., v.2, n. 1, p. 98-110, jan./jun. 1999 
que, dentro do novo quadro, o desenvolvimento ou subdesenvolvimento de um país passa cada vez mais a depender de sua localização hierárquica na divisão do trabalho mundial do que propriamente de sua própria taxa de desenvolvimento interno.

Pela vida do reconhecimento da diversidade inerente ao processo de globalizaçãoe também que alguns autores argumentam que a dinâmica do todo não se distribui de forma igual pelas partes, as quais tanto produzem e reproduzem seus próprios dinamismos, como assimilam diferentemente os dinamismos provenientes da sociedade global, expressando diversidades, localismos e identidades.

Traçando um paralelo entre tais teses e o reconhecimento do papel fundamental da informação dentro do conjunto dos atuais fenômenos que influenciam a economia, sociedade e cultura mundial, alguns autores vêm manifestando suas preocupações com o advento de uma era onde novas (e possivelmente ainda mais complexas) disparidades podem se fazer presentes. Uma tradução simplificada de tais preocupações é colocada como a possibilidade de substituir as atuais desigualdades identificadas entre países industrializados e não industrializados por outra separando países ricoss e pobres em informação.

Lojkine (1995) por exemplo, argumenta que a chamada revolução informacional "constitui o anúncio e a potencialidade de uma nova civilização" (p. 11), dentro da qual configura-se uma nova divisão internacional do trabalho: entre os que têm o monopólio do pensamento e aqueles que são excluídos deste exercício; entre aqueles que decidem e aqueles que executam.

Aponta-se, portanto, para a existência de novas formas de vínculos, imperialismos, dependências e interdependências no novo cenário, assim como centros de poder atuando em escala global que sobrepassam soberanias e hegemonias. Incluem-se, aqui, não apenas os blocos geopolíticos e os sistemas econômicos regionais, mas as próprias empresas transacionais, e os organismos internacionais tais como ONU, FMI, Banco Mundial etc. Concentrando parte maior das atenções encontra-se a discussão sobre o papel das grandes empresas transacionais que - em suas redes, alianças, operações e recursos mundiais - se transformaram em estruturas mundiais de poder, dispondo de condições consideradas como suficientes para imporem-se aos diferentes regimes políticos, às diversas estruturas estatais e aos distintos projetos nacionais.

Comun. Inf., v.2, n. 1, p. 98-110, jan./jun. 1999 


\section{4}

Esses são aspectos de importância inolvidável. Porém, como o objetivo principal deste trabalho é o de discutir a associação entre a difusão das novas tecnologias da informação com a atual fase de aceleração do processo de globalização e, dentro deste novo quadro, a coformação de blocos regionais, a discussão a seguir centrar-se-á neste último tema.

\section{Tecnologias da informação, globalização e a conformação de blocos regionais}

Na literatura sobre globalização e regionalização aponta-se para a estreita sinergia entre a atual fase de aceleração do processo de globalização, o advento do novo paradigma técnico-econômico das tecnologias da informação e a conformação de blocos. Neste sentido, chama-se a atenção para o fato de os países e instituições hegemônicos terem, nos últimos anos, intensificado sua ações - objetivando aglutinar forças formando blocos, assim como alianças de todo o tipo - visando garantir proteção para o espaço que conquistaram. Tais formas são vistas como contribuindo para:

- aumentar as chances de reduzir as incertezas, riscos e custos asociados a momentos de transição e reestruturação;

- aumentar e fortalecer a competitividade do todo, assim como das partes, de forma a reunir melhores condições de enfrentamento dos novos desafios impostos pelo novo cenário;

- diminuir as possibilidades de novos atores aproveitaram o período de grandes e profundas incertezas e transformações (no qual o regime de apropriação é seriamente enfraquecido, assim como o são as chamadas barreiras à entrada, dando margem a abertura de 'janelas de oportunidades'). ${ }^{3}$

No entranto, o que mais se destaca nas análises realizadas a respeito da atual tendência de formação de blocose alianças é a conclusão de que tal fenômeno não pode ser considerado como transitório, isto é, como uma resposta temporária a um momento de transição e reestruturação. Ao contrário, a conclusão maior a que se chega é a de que esse fenômeno está estreitamente associado às características dos novos tempos.

Comun. Inf., v.2, n. I, p. 98-110, jan./jun. 1999 
Nesta perspectiva, tal nova conformação geopolítica é vista como resposta dada aos novos requisitos. Assim, na atual fase do processo de globalização destaca-se a pararalela formação de vários sistemas geopolíticos e econômicos regionais, nos quais as economias e sociedades nacionais são integradas, criando-se novas condições para a organização e desenvolvimento das forças produtivas.

Alguns autores notam, inclusive, que na verdade é apenas aparente o paradoxo entre globalização e regionalização. Neste sentido, a regionalização, ao invés de ser vista como um obstáculo à globalização, é entendida como um processo por meio do qual a globalização recria a nação, visando conformá-la à dinâmica de uma economia crescentemente transnacional.

Conforme apontado, por exemplo, por Ianni (1996), ao resumir a contribuição de diferentes autores a respeito desta questão: "redesenham-se fronteiras, redefinem-se políticas econômicas, rearticulam-se forças produtivas, animam-se atividades econômicas novas, criam-se outras modalidades de organização do trabalho e da produção, reforma-se o estado, modifica-se o significado da sociedade civil e da cidadania e alteram-se as condições de soberania e hegemonia" (pp. 128-9).

Cabe aqui também comentar a contribuição daqueles autores que - como Reich (1993) e Ortiz (1996) - argumentam que não se pode esquecer que a concepção de economias e estados nacionais são relativamente recentes e cujo desenvolvimento encontra-se intimamente associado à expansão do capitalismo.

Ortiz (1996), por exemplo, em suas 'anotações sobre a mundialização e a questão nacional' ressalta que "o mundo nacional é fruto do industrialismo, de um tipo de formação social que faz da mobilidade uma das suas características principais. Neste sentido, a sociedade industrial, que é nacional, se diferencia radicalmente das sociedades agrárias passadas, nas quais os limites das culturas, das trocas e das fidelidades políticas encontravam-se confinados às regiões particulares. $\mathrm{O}$ mundo do Antigo Regime era constituído por unidades autônomas, díspares entre si... A Revolução Industrial, conjuntamente com as revoluções políticas, rompe este quadro. Eliminando os estamentos, elas promovem a circulação dos cidadãos, das mercadorias e das idéias. A nação se realiza portanto através da modernidade. Ela é um tipo de organização cuja base material corresponde ao industrialismo" (p.45).

Comun. Inf., v.2, n. 1, p. 98-110, jan./jun. 1999 
106

Tendo em vista as características e os novos desafios impostos pela nova ordem mundial, conforme discutidos acima, a seguir será examinada a experiência do bloco geopolítico-econômico (e não apenas comercial) há mais tempo estruturado e ativo - a União Européia. A análise de tal cạso oferece exemplos e lições de extrema relevância, uma vez que contempla-se a definição e a implementação de políticas do bloco como um todo, diretamente articulando políticas nacionais e coordenando as diferentes orientações de desenvolvimento econômico, industrial, social e informacional.

\section{A experiência da União Européia}

Conforme apontado por recente documento sobre política de informação britânica ${ }^{4}$, as primeiras propostas para o estabelecimento de uma ampla política para a área de informação a ser implementada pela União Européia podem ser encontradas no denominado Delors' White Paper. Tal documento, intitulado Growth, Competitiveness and Employment: the challenges and ways forward into the 21 th century, foi publicado em dezembro de 1993.

$\mathrm{O}$ documento $(\mathrm{i})$ propõe uma estratégia geral para melhorar a situação econômica da Europa e, em particular, diminuir o nível de desemprego na região; (ii ) advoga especificamente o desenvolvimento de uma infra-estrutura de redes de informação, baseando-se na noção norte-americana de Infra-estrutura Nacional de Informações.

Após discussão e aprovação desses princípios gerais, um membro da Comissão Européia - Martin Bangeman - encarregou-se de desenvolver as propostas. Este criou um grupo de empresários para definir as ações e estratégias prioritárias. Como resultado foi produzido, em 1994, o Bangeman Report Europe and the Global Information Society, que se trata de uma proposta de desenvolvimento liderada pelo setor privado.

Tal proposta foi aprovada pelos chefes de estado dos diferentes países e foi, em seguida, desenvolvido um plano de ação denominado Europe's way to information society: an action plan - o qual, na verdade, é visto como objetivando reunir uma série de outros programas e atividades relacionados à área de informação a cargo da Comissão. Assim, o plano de ação estabelece quatro áreas prioritárias:

Comun. Inf., v.2, n. I, p. 98-110, jan./jun. 1999 
- desenvolvimento de uma estrutura legal e regulatório;

- apoio ao desenvolvimento de redes de informação, serviços básicos e conteúdos;

- atenção a aspectos sociais e culturais;

• promoção da sociedade da informação.

Em 1995, a Comissão reconheceu que:

i. o Relatório Bangemann estava, na verdade, mais preocupado em tratar da questão da informação sobre o prisma de uma política de desenvolvimento industrial, buscando propor um modelo de liderança do setor privado;

ii. havia muitos aspectos sociais e políticos exigindo semelhante atenção. Como resultado foi criado o Grupo de Especialistas de Alto Nível (formado principalmente por professores e pesquisadores) para avaliar as implicações, impactos e desafios sociais associados à transição para uma sociedade intensiva em informação.

O relatório final do grupo foi disponibilizado em 1996, sob o título de Building the European Information Society for Us All.

Neste último relatório, manifesta-se a preocupação de que não se repita o padrão de disparidades e exclusão configurado a partir da Revolução Industrial, separando sociedades industrializadas daquelas outras sub-industrializadas. Neste sentido, reconhece-se a responsabilidade da Europa tanto no desenho do padrão que acompanhou o advento e desenvolvimento industrial, quanto agora na construção do novo padrão em conformação associado ao desenvolvimento da sociedade da informação. A idéia é evitar a formação de um mundo separando os países e segmentos sociais entre ricos e pobres em informação, onde podem surgir sociedades limitadas ou ilhadas em termos de acesso e uso de informação.

Tendo em vista este objetivo mais amplo, reconhece-se a importância estratégia de promover o desenvolvimento de uma infra-estrutura completa de informação, pois entende-se que a mesma é condição sine-qua-non para o progresso atual. Neste caso, são inclusive feitas referências às conquistas feitas pelos EUA e comparadas as dificuldades e desvantagens competitivas da Europa.

Comun. Inf., v.2, n. I, p. 98-110, jan./jun. 1999 


\section{8}

No entanto, coloca-se ênfase fundamental no entendimento de que isso por si só não basta. Há que se promover também a geração de conhecimentos que permitam aos diferentes componentes da sociedade fazer uso das informações disponibilizadas.

Assim, o relatório propõe que se equacione uma estratégia política que não se restrinja a equacionar os sérios desafios relacionados à montagem das novas e custosas infra-estruturas de informação, mas que vise promover tanto o acesso à informação quanto, principalmente, o acesso ao conhecimento. São, portanto, ressaltadas as importantes mudanças sociais exigidas pelo novo cenário e discutidas as novas necessidades de programas de capacitação e recapacitação profissional.

Nesta linha, destacam-se centralmente os necessários diagnóśticos e ajustes relacionados ao surgimento e crescimento das novas habilidades e profissões que uma sociedade da informação exige para que funcione como uma real sociedade do conhecimento.

\section{Considerações finais}

A título de considerações finais, propomos a reflexão sobre os seguintes pontos, que a leitura das propostas enunciadas acima nos colocou:

- não poderíamos concluir que tais propostas e recomendações parecem fazer mais senso ainda se lembrarmos que:

- um dos desafios que o novo paradigma traz é que dispomos de uma forma ainda muito rudimentar de mensurare dar preço à informação e ao conhecimento - e, portanto, possibilitar sua privatização e comercialização como se fossem mercadorias? Mas que certamente, nos dias atuais, muito mais já foi desenvolvido no que se refere à informação?

- portanto, este prisma da questão oferece uma possível interpretação de porque os interesses privados têm se concentrado mais propriamente no processo de 'commoditização' de informações e exigido a montagem das necessárias infra-estruturas que permitam aos consumidores acessar os novos bens e serviços produzidos (e principalmente aqueles que já o são massivamente)?

- uma sociedade da informação sem conhecimento não se transformaria realmente numa Torre de Babel como coloca Freeman (1995)? 
Ou então - como coloca Virilio (1996) - numa sociedade ainda mais intensamente poluída (por uma enxurrada de informação) e, desta vez, atacando de forma fatal um órgão humano especial (o cerébro)?

- e assim, poderíamos inclusive avançar um pouco mais e nos indagar se:

- não caberia aos Estados (como forma de representação dos anseios e pressões sociais), nas suas diferentes dimensões, operar no sentido de facilitar o ajuste imposto pelos novos desafios não cuidando apenas das necessidades do setor privado mas, principalmente, das necessidades das sociedades como um todo?

- ou - como Estados minimalistas que em geral se tornaram - não deveriam os mesmos concentrar seus apoios exclusivamente em atividades e áreas desprivilegiadas pelos capitais privados? Mesmo que tal significasse um ritmo menos intenso de crescimento econômico, mas que contemplasse um nível mais amplo de desenvolvimento social?

\begin{abstract}
This article debates the new information environment and the impact of new technologies, especially emphasizing its relations with one world economic block, the Union European.
\end{abstract}

Key words: globalization, technologies of information, world economic block, Union European.

\title{
Notas
}

1. Ver, dentre outros e para uma resenha, Lastres, 1997.

2. Fiori, 1993 e Ianni, 1996.

3. Ver dentre outros, Chesnais, 1996 e Lastres, 1997.

4. Moore, 1997.

\section{Referências bibliográficas}

ALBAGLI, S. Informação e Desenvolvimento Sustentável; novas questões para o século XXI. Ciência da Informação, v. 24, n. 1, p. 119-25, 1995.

ARAÚJO, V. M. R. H. Informação e globalização: algumas considerações. $C i$ ência da Informação, v. 26, n. 3, p. 233-4, 1997.

CHESNAIS, F. A mundialização do capital. Rio de Janeiro: Xamã, 1996.

COUTINHO, L. A fragilidade do Brasil em face da globalização. In: BAUMANN, R. O Brasil e a economia global. Rio de Janeiro: Campus SOBEE II, 1996. p. 219-237. 
COUTINHO, L., CASSIOLATO, J. E. e SILVA, A. L. (coord.). Telecomunicações, globalização e competitividade. Campinas: Papirus, 1995.

EUROPEAN COMMISSION, INFO 2000: The Markets for Electronic Information Services in the European Economic Area, DG XIII. Bruxelas, 1995.

FIORI, J. L. A globalização e a novíssima dependência. Rio de Janeiro: UFRJ: Instituto de Economia, 1995. (Texto para discussão n. 343).

FIORI, J. L. 'Globalização, estados nacionais e políticas públicas', Ciência hoje, vol. 16, n. 96, pp. 24-31 (Rio de Janeiro, 1993).

FREEMAN, C. Information Highways and Social Change. [s.I.]: IDRC, 1995. mimeo.

FREEMAN, C., SOETE, L. (ed.). Information tecnology and employment. Maastrich: Universitaire Pers, 1993.

HUMBERT. Strategic industrial policies in a global industrial system. Review of International Political Economy, v. 1, n.3, p. 445-63, Autumn, 1994.

IANNI, O. A era do globalismo. Rio de Janeiro: Civilização Brasileira, 1996.

IANNI, O. Teorias da Globalização. Rio de Janeiro: Civilização Brasileira, 1995.

LASTRES, H. M. M. A globalização e o papel das políticas de desenvolvimento industrial e tecnológico. Brasília: Cepal/Ipea: Projeto Novas Políticas de Competitividade, 1997.

MOORE, N. Policies for an Information Intensive Britain. Bulletin of the American Society for Information Science. Washington, v. 17, n. 4, p. 10-11, Apr. 1991.

MYTELKA, L., DELAPIERRE, M. The Alliance Strategies of European Firms in the Information Technology Industry and the Role of Esprit. Journal of Common Market Studies, v. 26, n.2, 1987.

ORTIZ, R. Anotações sobre a mundialização e a questão nacional. Sociedade e Estado. Braasília: UNB-Depto de Sociologia, v. 11, n.1, 1996.

PEREZ, C. Structural change and the assimilation of new technologies in the economic and social systems. Futures, v. 15, n. 5, p. 357-75, 1983.

REICH, R. O trabalho das nações. São Paulo: Educator, 1994.

TOURAINE, M. Le bouleversement du monde. Paris: Ed. Seuil, 1995.

U. K. Development of the information society: an international analysis. Londres: Department of Trade and Industry, 1996.

VIRILIO, P. A arte do motor: São Paulo: Estação Liberdade, 1996.

Comun. Inf., v.2, n. 1, p. 98-110, jan./jun. 1999 